\title{
Fluid inclusions from active and fossil hydrothermal system in Chile
}

\author{
D MONCADA $^{1}$
}

${ }^{1}$ Department of Geology, University of Chile, Plaza Ercilla 803, Santiago, Chile,dmoncada@ing.uchile.cl

Our understanding of the physical and chemical processes associated with formation of both active terrestrial hydrothermal systems and their fossil equivalents has advanced significantly through a combination of studies of well-characterized deposits. Chile host numerous geothermal, epithermal precious and base metal, polymetallic, and porphyry cooper deposits. Here we describe the fluids and fluid inclusions from the north to the south of Chile. The geothermal systems, Irruputuncu and Olca located Northern part of Chile, at more than 4,000 meters above sea level. Thin sections from samples of these geothermal systems were examined using a petrographic microscope, and fluid inclusion and mineralogical evidence for boiling of the hydrothermal fluids was recorded. Located in the same area the Collahuasi mining district host the Rosario porphyry copper-molybdenum deposit. Results shows evidence of fluid inclusions assemblages (FIAs) in quartz and were classified at room temperature: (1) Halite-barring inclusions indicating high salinity fluids; (2) Chalcopyrite daughter mineral; (3) Liquid-rich aqueous inclusions with trapped solid; (4) Coexisting halite bearing and vapor-rich inclusions with a broad range in liquid-to-vapor ratios indicating fluid-phase separation; (5) Coexisting liquid-rich and vapor-rich inclusions with a broad range in liquid-to-vapor ratios indicating fluid-phase separation; (6) Vapor-rich inclusions indicating flashing of the fluid. Situated within the Coastal Range of Central Chile the epithermal precious metal deposit. The polymetallic Alhué mining district shows increments in $\mathrm{Ag}-\mathrm{Cu}$ related to hypersaline fluids $(\sim 33 \mathrm{wt} . \% \mathrm{NaCl})$ in the Lorena vein. The Maqui vein shows Ag-Ba-Cu-Mn-Fe related to low salinity fluids $(\sim 5 \%$ wt. $\% \mathrm{NaCl})$. The Tribuna Este shows Ag-Al-Fe-Cd related to intermediate salinities ( $\sim 18 \mathrm{wt}$. $\% \mathrm{NaCl})$. Finally, The Chilean Patagonia hosts numerous polymetallic and epithermal environment resources, among these the Cerro Bayo District in the Aysén Region. A detailed fluid inclusion petrography, gangue mineral textural characterization and mineralization paragenesis study was conducted on the ore bearing Fabiola and Dagny vein. Areas of most intense boiling are associated with colloform and bladed calcite textures. These observations were incorporated into a geographical information platform to define potential geospatial correlations between the fluid inclusion characteristics, the gangue mineral textures and ore grades. Acknowledge: CONICYT 11170210, FONDEQUIP 170103. 